\title{
POST-FIRE SAFETY OF CONCRETE COLUMNS An Engineering-Oriented Reliability-Based Assessment Tool
}

\author{
Ruben Van Coile ${ }^{\mathrm{a}}$, Robby Caspeele ${ }^{\mathrm{a}}$, Luc Taerwe ${ }^{\mathrm{a}}$ \\ ${ }^{a}$ Ghent University, Faculty of Engineering and Architecture, Department of Structural Engineering, Ghent, Belgium
}

\begin{abstract}
Concrete insulation properties and chemo-physical stability up to $400-500^{\circ} \mathrm{C}$ generally prevents concrete structures from collapsing in fire. Consequently, the safety assessment of reinforced concrete members - and specifically columns - is a must past any severe fire. This post-fire assessment should be based on reliability considerations, as many uncertainties are associated with both the fire evolution and the residual mechanical properties of the materials. The reliability considerations should clarify whether the column has an adequate safety level for its intended postfire use. An easy-to-use reliability-based assessment method is presented in this paper to determine the bearing capacity of a reinforce concrete column after a fire, and the safety performance of the method is investigated. The proposed method is shown to be at the same time easy to use and very reliable.
\end{abstract}

Keywords: post-fire assessment, concrete column, safety level, residual load bearing capacity

\section{INTRODUCTION}

Often fire exposure is not so severe as to result in structural failure of the concrete structure. Consequently, a post-fire assessment is necessary to determine if the concrete members can be used without repair or rehabilitation or are in need of strengthening. Up to now only a limited number of studies focusses on this post-fire assessment, see e.g. (Venazi et al., 2009), (Kodur et al., 2013), (Robertson et al., 2015) and (Ahmed and Khalid, 2015). These studies are based on a deterministic calculation of the load bearing capacity and do not consider the desired level of safety. The safety level is, however, of paramount importance because also the design of new structures is fundamentally based on obtaining a target reliability index or safety level. For example, EN 1990 (CEN, 2002) specifies a target reliability index of 3.8 for the design of new members (50 year reference period and moderate consequences of failure). Furthermore, uncertainties are associated with both the fire duration and the effect of elevated temperatures on the residual mechanical properties. If the post-fire assessment of the concrete member is to be acceptable, it has to be in agreement with the fundamental considerations used for the design of new concrete members. Consequently, the post-fire assessment is necessarily based on reliability considerations.

An easy-to-use and reliability-based method for the post-fire assessment of concrete slabs has been presented in (Van Coile et al., 2014). The method is based on a limited number of analytical equations and a pre-calculated graph, which together allow to determine the allowable load on a slab after fire exposure, considering a specified target reliability index $\beta_{t}$ (for example $\beta_{t}=3.8$ ). In this paper an adaptation of the method for fire-exposed concrete columns is summarily presented, and the obtained safety level (i.e. the performance of the method) is evaluated.

\section{METHOD FOR THE POST-FIRE ASSESSMENT OF CONCRETE COLUMNS}

The proposed post-fire assessment method utilizes a pre-calculated graph, called an Assessment Interaction Diagram or AID, in order to obtain a specified target reliability index $\beta_{t}$. The AID is based on the limit state function $Z$, given by $E q$. (1) where $R$ is the resistance (including model uncertainties $K_{R}$ and $K_{E}$ ), $G$ is the permanent load effect, and $Q$ is the imposed load effect. While $R$ is described by a lognormal distribution, $G$ follows a normal distribution and $Q$ a Gumbel distribution in accordance with (Holický and Sýkora, 2010). The permanent load effect $G$ and the 
imposed load effect $Q$ are related by the load ratio $\chi=Q_{k} /\left(Q_{k}+G_{k}\right)$, with the index $k$ indicating characteristic values. As $G_{k}$ (predominantly self-weight) is well known or can be easily assessed, determining the maximum allowable load after fire reduces to determining the maximum allowable characteristic value $Q_{k}$ of the imposed load.

The AID for $\beta_{50, t}=3.8$ (50 year reference period) is given in Fig. 1. Note that the reference period determines the period over which the uncertain maximum for the imposed load $Q$ is determined, and does not relate directly to the design life for the structure.

When the mean value $\mu_{R}$ and coefficient of variation $V_{R}$ of $R$, and the mean value $\mu_{G}$ of $G$ are known, the point in the AID given by $\mu_{R} / \mu_{G}$ on the vertical axis and $V_{R}$ on the horizontal axis indicates the maximum allowable load ratio $\chi_{\max }$ through the pre-calculated curves. The $\chi_{\max }$ is directly related to the maximum acceptable characteristic value of the imposed load $Q_{k}$ through $E q$. (2), with $G_{k}=\mu_{G}$ as specified by (Holický and Sýkora, 2010). Note that interpolation can be used when the point in the AID does not correspond exactly with one of the given curves. Furthermore, the AID is indifferent to the type of structural member considered, and is generally applicable.

$$
\begin{gathered}
Z=R-(G+Q) \\
Q_{k, \text { max }}=\frac{\chi_{\text {max }}}{1-\chi_{\max }} G_{k}=\frac{\chi_{\max }}{1-\chi_{\max }} \mu_{G}
\end{gathered}
$$

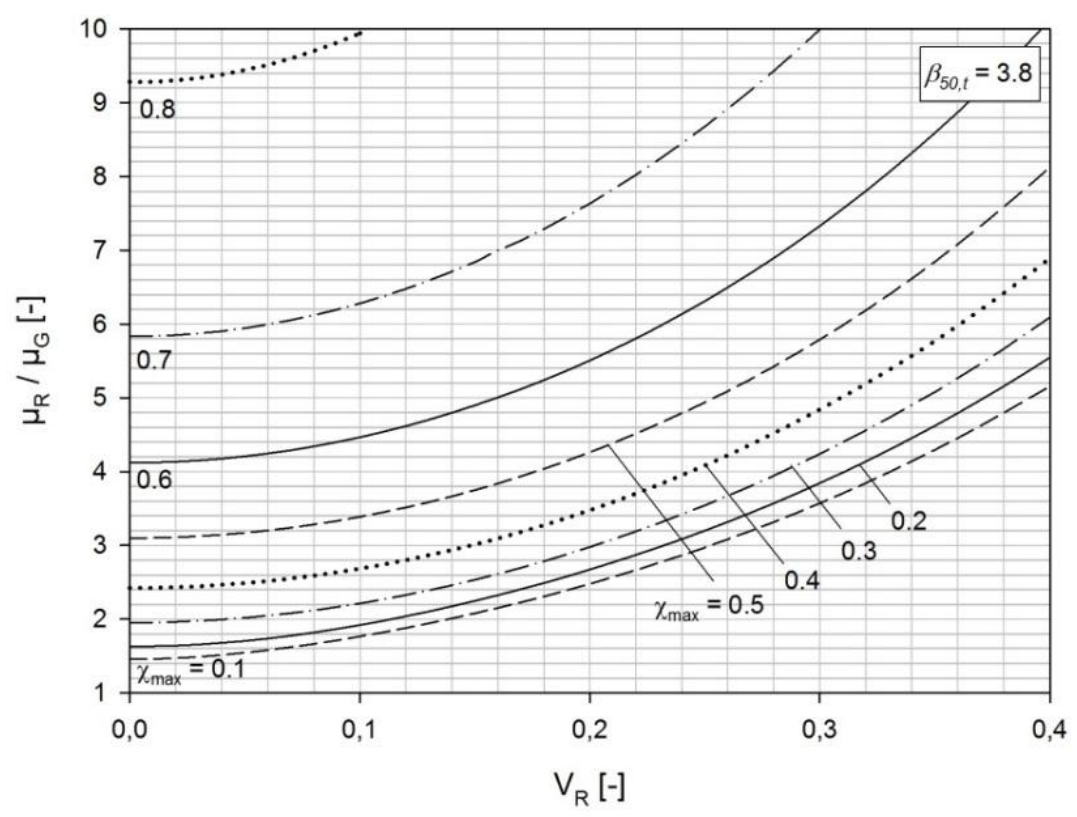

Fig. 1 Assessment Interaction Diagram for $\beta_{t}=3.8,50$ year reference period

In order to apply the AID for determining the maximum allowable characteristic value of the imposed normal force $N_{Q k}$ on a centrically loaded square concrete column after fire exposure, the mean and coefficient of variation of the residual normal force capacity $N_{R \text {, res }}$ have to be assessed. This assessment is based on the well-known "reduced- or effective-section approach" which relies on a reference isothermal line (in general the $500^{\circ} \mathrm{C}$ isotherm and therefore the method is often referred to as the " $500^{\circ} \mathrm{C}$ method" - see for instance (Kodur et al., 2013) for an application to the post-fire assessment of columns). Probabilistic analyses supporting the use of the $500^{\circ} \mathrm{C}$ isotherm for the post-fire assessment of concrete columns have been presented in (Van Coile, 2015).

According to this $500^{\circ} \mathrm{C}$ method, the strength of the concrete heated above $500^{\circ} \mathrm{C}$ is neglected, while the remaining concrete is taken into account considering the initial $20^{\circ} \mathrm{C}$ compressive strength $f_{c, 20^{\circ} \mathrm{C}}$. For the reinforcement the local temperature-dependent residual yield stress is taken into 
account. The applied model for the temperature dependent reduction factor $k_{f y, r e s}$ for the residual yield stress has been presented in detail in (Van Coile et al., 2014), and is based on (fib, 2008).

Considering a square concrete column exposed to fire from four sides, the analytical formula for the residual normal force capacity is given by $E q$. (3), with parameters as given in Table 1 and $i_{500}$ the depth of the $500^{\circ} \mathrm{C}$ isotherm. The parameters $k_{f y, r e s}$ and $i_{500}$ are dependent on the temperature distribution inside the column cross-section.

$$
N_{R, \text { res }}=A_{s} k_{f y, r e s} f_{y, 20^{\circ} \mathrm{C}}+\left(b-2 i_{500}\right)^{2} f_{c, 20^{\circ} \mathrm{C}}
$$

Table 1 Parameters for the investigated concrete column

\begin{tabular}{|c|c|c|c|c|}
\hline Property & Distribution & Dimension & Mean & CoV \\
\hline $20^{\circ} \mathrm{C}$ concrete compressive strength $f_{c, 20^{\circ} \mathrm{C}}$ & $\mathrm{LN}$ & $\mathrm{MPa}$ & 78.6 & 0.15 \\
\hline $20^{\circ} \mathrm{C}$ reinforcement yield stress $f_{y, 20^{\circ} \mathrm{C}}$ & $\mathrm{LN}$ & $\mathrm{MPa}$ & 581.4 & 0.07 \\
\hline Concrete cover $c$ & $\mathrm{Beta}[\mu \pm 3 \sigma]$ & $\mathrm{mm}$ & 25 & $0.20\left(\sigma_{c}=5 \mathrm{~mm}\right)$ \\
\hline Reinforcement area $A_{s}$ & $\mathrm{~N}$ & $\mathrm{~mm}^{2}$ & $3217(4 \varnothing 32)$ & 0.02 \\
\hline Column width $b$ & $\mathrm{~N}$ & $\mathrm{~mm}$ & 300 & - \\
\hline Total model uncertainty $K_{T}$ & $\mathrm{LN}$ & - & 0.9 & 0.17 \\
\hline Model uncertainty for the resistance $K_{R}$ & $\mathrm{LN}$ & - & 1.0 & 0.1 \\
\hline Model uncertainty for the load effect $K_{E}$ & $\mathrm{LN}$ & - & 1.0 & 0.1 \\
\hline Permanent load effect $N_{G}$ & $\mathrm{~N}$ & $\mathrm{kN}$ & $N_{G k}$ & 0.1 \\
\hline Imposed load effect $N_{Q}$ & $\mathrm{Gumbel}$ & $\mathrm{kN}$ & $0.6 N_{Q k}$ & 0.35 \\
\hline
\end{tabular}

If the fire can be related to a known fire load and ventilation characteristics, and a numerical thermal calculation tool is available, a single value for $i_{500}$ can be determined directly, as well as a mean value and uncertainty for $k_{f y, r e s}$ (considering the uncertain concrete cover). Alternatively, the fire can be related to a single (conservatively assessed) ISO 834 standard fire duration, and the temperature profiles given in Annex A of EN 1992-1-2 (CEN, 2004) can be applied. If the fire severity is not known, probabilities can be assigned to the ISO 834 fire durations given in Annex A of EN 1992-1-2 through calculation or expert judgment. This is elaborated in more detail in (Van Coile, 2015), together with the detailed instructions for calculating $\mu_{k f y, \text { res }}$ and $V_{k f y}$,res.

The mean value $\mu_{R}$ and the coefficient of variation $V_{R}$ are determined by applying Taylor approximations. This results in the following set of analytical formulas:

$$
\begin{gathered}
\mu_{R} \approx \mu_{K T} \mu_{A s} \mu_{k f y, r e s} \mu_{f y, 20^{\circ} \mathrm{C}}+\mu_{K T}\left(\mu_{b}-2 \mu_{i 500}\right)^{2} \mu_{f c, 20^{\circ} \mathrm{C}} \\
V_{R} \approx \frac{\sqrt{\sum_{i=1}^{7} S_{i}}}{\mu_{R}} \\
S_{1}=\left(\mu_{A s} \mu_{k f y, r e s} \mu_{f y, 20^{\circ} \mathrm{C}}+\left(\mu_{b}-2 \mu_{i 500}\right)^{2} \mu_{f c, 20^{\circ} \mathrm{C}}\right)^{2} \sigma_{K T}^{2} \\
S_{2}=\left(\mu_{K T} \mu_{k f y, r e s} \mu_{f y, 20^{\circ} \mathrm{C}}\right)^{2} \sigma_{A s}^{2}
\end{gathered}
$$




$$
\begin{gathered}
S_{3}=\left(\mu_{K T} \mu_{A s} \mu_{f y, 20^{\circ} \mathrm{C}}\right)^{2} \sigma_{k f y, r e s}^{2} \\
S_{4}=\left(\mu_{K T} \mu_{A s} \mu_{k f y, r e s}\right)^{2} \sigma_{f y, 20^{\circ} \mathrm{C}}^{2} \\
S_{5}=\left(\mu_{K T}\left(\mu_{b}-2 \mu_{i 500}\right)^{2}\right)^{2} \sigma_{f c, 20^{\circ} \mathrm{C}}^{2} \\
S_{6}=\left(2 \mu_{K T}\left(\mu_{b}-2 \mu_{i 500}\right) \mu_{f c, 20^{\circ} \mathrm{C}}\right)^{2} \sigma_{b}^{2} \\
S_{7}=\left(-4 \mu_{K T}\left(\mu_{b}-2 \mu_{i 500}\right) \mu_{f c, 20^{\circ} \mathrm{C}}\right)^{2} \sigma_{i 500}^{2}
\end{gathered}
$$

Considering as an example different deterministic ISO 834 fire durations, evaluation of the above equations for the column of Table 1, results in $\mu_{R}$ and $V_{R}$ as given in Table 2.

Table $2 \mu_{R}$ and $V_{R}$ for the column of Table 1, for different ISO 834 standard fire durations

\begin{tabular}{|c|c|c|c|c|}
\hline ISO 834 standard fire duration $\boldsymbol{t}_{\boldsymbol{E}}[\mathrm{min}]$ & 30 & 60 & 90 & 120 \\
\hline $\boldsymbol{\mu}_{\boldsymbol{R}}[\mathrm{kN}]$ & 7227 & 6390 & 5639 & 4640 \\
\hline $\boldsymbol{V}_{\boldsymbol{R}}[\mathrm{kN}]$ & 0.21 & 0.21 & 0.21 & 0.21 \\
\hline
\end{tabular}

When the results of Table 2 are combined with a case-specific assessment of the permanent load $\mu_{G}$ $\left(=N_{G k}\right)$, the AID of Fig. 1 can be applied and the maximum allowable imposed load determined. In Fig. 2 the method is applied for a very large number of $N_{G k}$, resulting in combinations of maximum allowable characteristic values of the permanent load effect $N_{G k, \max }$ and the imposed load effect $N_{Q k, \max }$. The curves "prior to fire" indicate the maximum allowable load combinations in accordance with the Eurocode methodology for the design of new concrete columns.

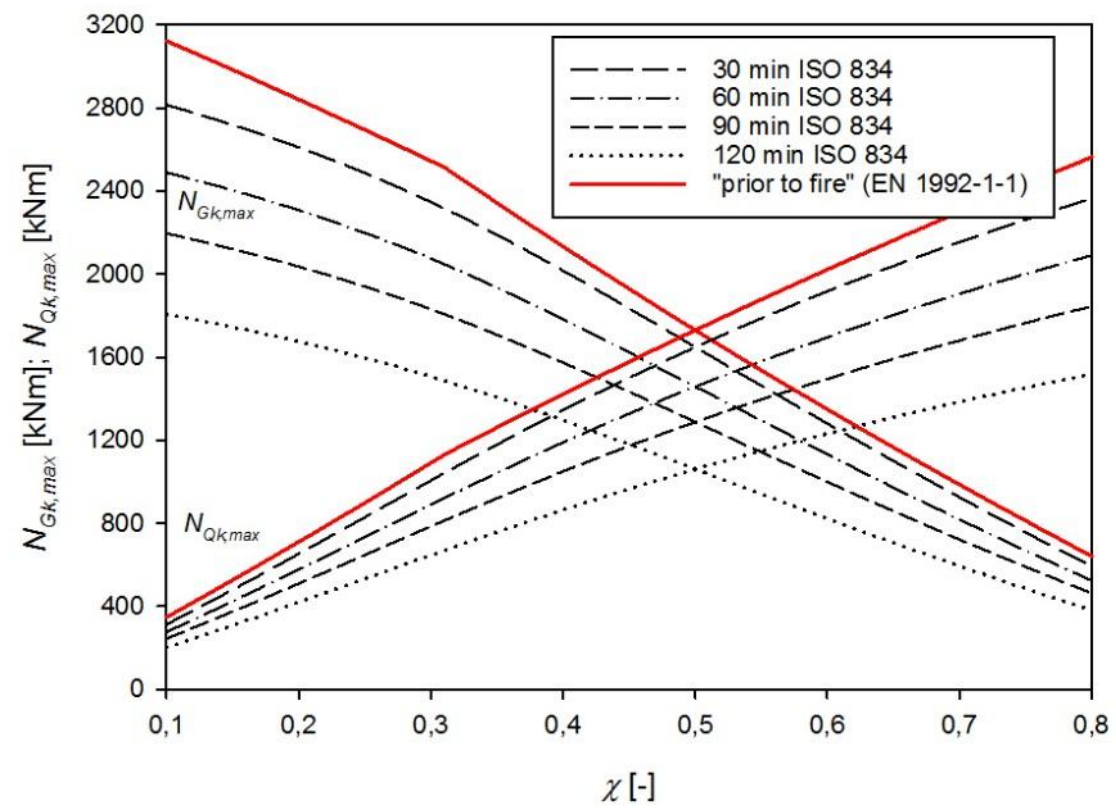

Fig. 2 Maximum allowable combinations for the characteristic values of the normal forces $N_{G k}$ and $N_{Q k}$. 


\section{EVALUATION OF THE SAFETY PERFORMANCE OF THE METHOD}

In order to evaluate the performance of the post-fire assessment method, the safety levels (reliability indices) associated with the calculated maximum allowable load combinations of Fig. 2 have to be determined and compared to the target reliability index of 3.8. To this end a numerical calculation tool is developed, similar to the model described in (Kodur and Dwaikat, 2008), but considering post-fire material models. Using Monte Carlo simulations, the distribution describing $N_{R, \text { res }}$ is determined. Results are visualized in Fig. 3, with A the observed histogram resulting from the simulations, and LN a lognormal approximation. Based on Fig. 3 and statistical tests, a lognormal approximation can be used to describe $N_{R \text {,res }}$ for the ISO 834 fire durations considered above.

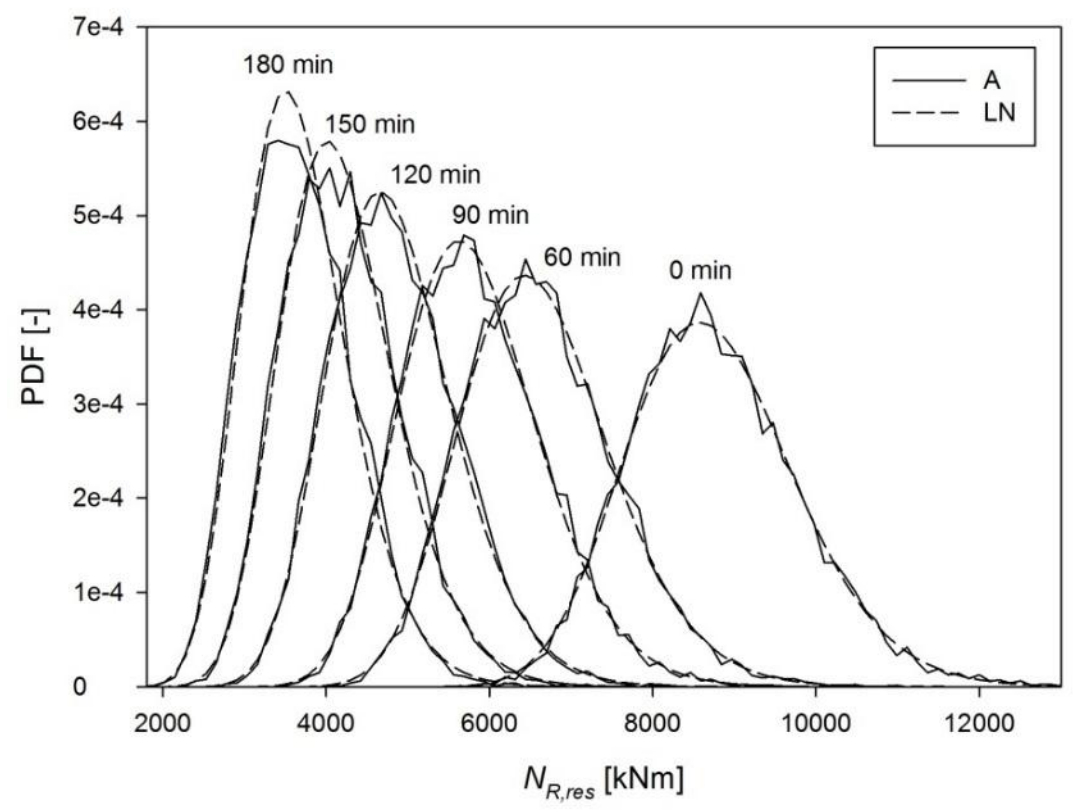

Fig. 3 Observed histogram A and lognormal approximation LN of $N_{R, \text { res }}$ for different ISO 834 durations.

Considering the lognormal distribution for $N_{R, \text { res }}$ and the lognormal model uncertainties $K_{R}$ and $K_{E}$ given in Table 1, the reliability indices associated with the maximum allowable load combinations of Fig. 2 can be determined, taking into account the limit state function of $E q$. (1), where $R=$ $K_{R} \cdot N_{R, \text { res }} / K_{E}$. Results are given in Fig. 4. It is observed that the maximum allowable load combinations indicated by the proposed post-fire assessment method result in a reliability index $\beta_{50}$, close to the target reliability index of 3.8. Furthermore, the observed deviations are on the safe side.

\section{CONCLUSIONS}

As fire introduces additional uncertainties in the calculation of the bearing capacity of reinforced concrete columns, and in order to adhere to the reliability-based approach adopted in the design of new structures, the assessment of the maximum allowable load for concrete columns after fire exposure should necessarily be based on reliability considerations. To this end an easy-to-use reliability-based method has been presented in this paper. As an example, maximum allowable load combinations (permanent load and imposed load) have been determined for a specific concrete column, for different ISO 834 standard fire exposures. The reliability index associated with these maximum allowable load combinations has been calculated using a numerical tool for determining the residual load-bearing capacity of concrete columns. It is observed that the obtained reliability index is close to the target value of 3.8 , while at the same time resulting in a conservative approximation. 


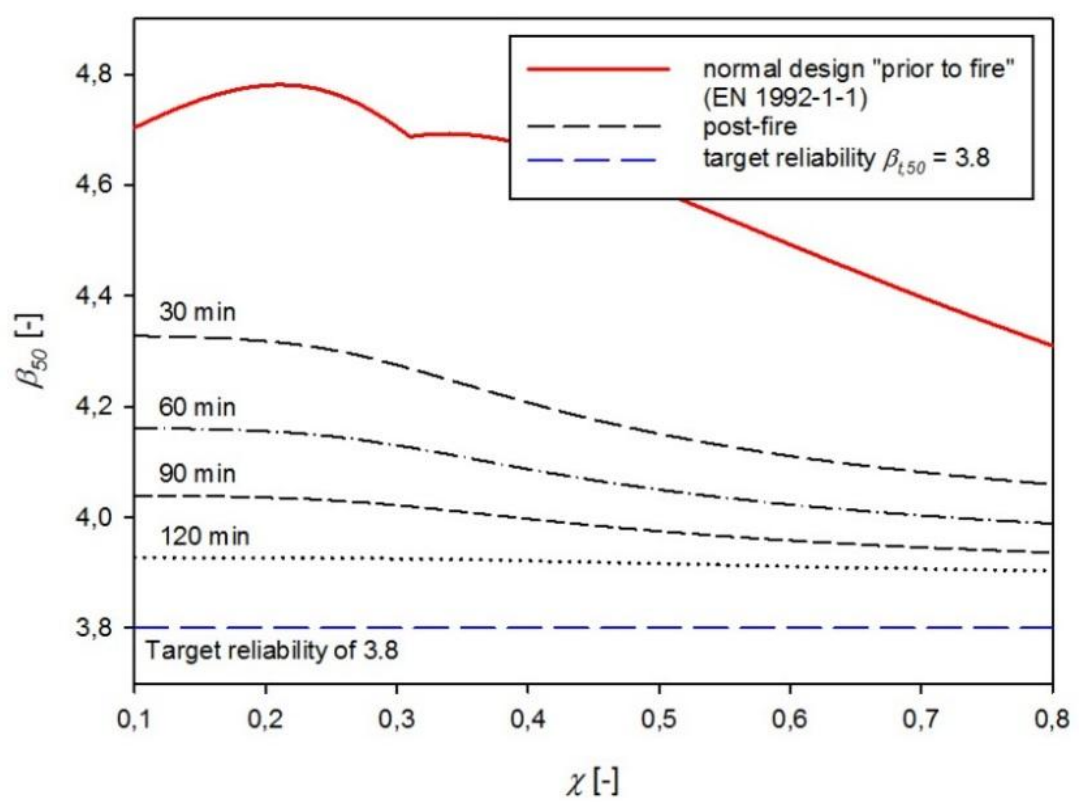

Fig. 4 Observed histogram 'A' and lognormal approximation 'LN' of $N_{R, \text { res }}$ for different ISO 834 durations.

\section{ACKNOWLEDGMENTS}

The authors wish to thank the FWO for the financial support on the research project "Probabilistic formulation of the structural reliability of concrete structures subjected to fire in relation to risk-based decision making and risk-transfer mechanisms".

\section{REFERENCES}

Ahmed, A., Khalid, M. 2015. Assessment and rehabilitation of fire damaged reinforced concrete building - a case study, in Proceedings of the Fifth International Workshop on Performance, Protection, and Strengthening of Structures under Extreme Loading (PROTECT2015), 28-30 June 2015, East Lansing, USA, p. 956-963.

CEN. 2002. EN 1990: Eurocode 0: Basis of structural design. European Standard.

Holický, M., Sýkora, M. 2010. Stochastic models in analysis of structural reliability, in International Symposium on Stochastic Models in Reliability Engineering, Life Sciences and Operation Management. 8-11 February 2010, Beer Sheva, Israel.

fib. 2008. fib Bulletin 46: State-of-art report: Fire design of concrete structures - structural behaviour and assessment.

Kodur, V.K.R., Dwaikat, M.B. 2008. A numerical model for predicting the fire resistance of reinforced concrete beams. Cement and Concrete Composites, 30, p. 431-443.

Kodur, V.K.R., Raut, N.K., Mao, X.Y., Khaliq, W. 2013. Simplified approach for evaluating residual strength of fire-exposed reinforced concrete columns. Materials and Structures, 46, p. 2059-2075.

Robertson, L., Gales, J., Stratford, T., Al-Merabi, A. 2015. Post-Fire Investigations of Prestressed Concrete Structures, in Proceedings of the Fifth International Workshop on Performance, Protection, and Strengthening of Structures under Extreme Loading (PROTECT2015), 28-30 June 2015, East Lansing, USA, p. 747-754.

Van Coile, R., Caspeele, R., Taerwe, L. 2014. Towards a reliability-based post-fire assessment method for concrete slabs incorporating information from inspection. Structural Concrete, 15, p. 395-407.

Van Coile, R. 2015. Reliability-Based Decision Making for Concrete Elements Exposed to Fire, PhD Thesis, Ghent University.

Venanzi, I., Materazzi, A. L., Zappia, M. 2009. Residual strength of R.C. buildings after a fire: A case study, in 2nd International Conference on Concrete Repair, Rehabilitation and Retrofitting. 24-26 November 2009, Cape Town, South-Africa, p. 247-248. 